Elsevier required licence: (C) <2019>. This manuscript version is made available under the CC-BY-NCND 4.0 license http://creativecommons.org/licenses/by-nc-nd/4.0/

The definitive publisher version is available online at

[https://www.sciencedirect.com/science/article/pii/S0048969719310447?via\%3Dihub] 


\title{
In situ reconstruction of long-term extreme flooding magnitudes and frequencies based on geological archives
}

Yuqin $\mathrm{Li}^{\mathrm{a}, \mathrm{b}^{*}}$, Chunchang Huang ${ }^{\mathrm{a}}$, Huu Hao Ngo ${ }^{\mathrm{b} *}$, Jiangli Pang ${ }^{\mathrm{a}}$, Xiaochun Zha ${ }^{\mathrm{a}}$, Tao

$$
\text { Liu }^{\mathrm{c}} \text {, Wenshan Guo }{ }^{\mathrm{b}}
$$

${ }^{a}$ School of Geography and Tourism, Shaanxi Normal University, Xi'an, Shaanxi

710119, PR China

${ }^{b}$ Faculty of Civil and Environmental Engineering, University of Technology, Sydney, NSW 2007, Australia

${ }^{c}$ Department of Hydrology and Atmospheric Sciences, University of Arizona, Tucson, Arizona 85721-0011, USA

\begin{abstract}
Extreme flooding magnitudes and frequencies are essentially related to assessment of risk and reliability in hydrological design. Extreme flooding and its discharge are highly sensitive to regional climate change. Presently, its discharge can be reconstructed by a geological archive or record along the river valley. Two units of typical extreme flooding deposits (EFDs) carrying long-term information preserved in the Holocene loess-palaeosol sequence were found at Xipocun (XPC), which is located in Chengcheng County, China. It is situated in the downstream section of the Beiluohe (hereafter BLH) River. Based on multiple sedimentary proxy indices (grain-size distribution (GSD), magnetic susceptibility (MS), and loss-on-ignition (LOI), etc.), EFDs were interpreted as well-sorted clayey silt in suspension. They were then deposited as a result of riverbank flooding in a stagnant environment during high water level. Through the Optically Stimulated Luminescence (OSL) dating


technique and stratigraphic correlations, chronologies of two identified extreme flooding periods were $7600 \sim 7400$ a B.P. and 3 200 3 000 a B.P. Two phases of extreme flooding occurrence under climate abnormality scenarios were characterized as having high frequencies of hydrological extremes in river systems. According to simulation and verification using the Slope-Area Method and Hydrologic Engineering Center's River Analysis System (HEC-RAS) model, the extreme flooding discharges at the XPC site were reconstructed between $9625 \mathrm{~m}^{3} / \mathrm{s}$ and $16635 \mathrm{~m}^{3} / \mathrm{s}$. A new long-term flooding frequency and peak discharge curve, involved gauged flooding, historical flooding at Zhuangtou station and in situ reconstructed extreme flooding events, was established for the downstream BLH River. The results improve the accuracy of low-frequency flooding risk assessment and provide evidence for predicting the response of fluvial systems to climate instability. Thus, this improves the analysis of the BLH River watershed.

Keywords: Extreme flooding deposits; In situ reconstruction; Magnitude; Long-term flooding frequency; Beiluohe River watershed

\section{Introduction}

Increasingly, magnitudes and frequencies of hydrological extremes in recent decades are seriously affecting ecosystems and social systems (IPCC, 2013; Taye et al., 2015). Extreme flooding that is usually considered a disaster caused by the inadequate capacity of riverbanks to contain high flows under semi-arid and 
semi-humid conditions (Xu et al., 2014; Zhang et al., 2015a). Statistics show that more than $40 \%$ of all natural disasters each year is attributed to extreme flooding and the trend in flooding damage has grown exponentially in the last few decades (Apurv et al., 2015). Fluvial extreme flooding is a perennial and recurrent problem in China. The reported number of extreme and severe flooding occurrences in China between 206 B.C. and 1949 was 1 092. These events on average occur every two years throughout China (Zhang et al., 2016). Global climate instability and prolonged rainfalls exert a powerful impact on regional extreme flooding events (Beniston et al., 2011; Stoffel et al., 2014). China's flood-related losses reach 113 billion renminbi (RMB) per year, making up $43.6 \%$ of the total losses caused by natural disasters, and have steadily increased since 1994 (Wang et al., 2014; Liu et al., 2016). In this context, the simulation of extreme flooding dynamic processes and exploration of what their triggers have become key issues.

Extreme flooding magnitudes and frequencies are essentially related to assessment of risk and reliability in hydrological design. The likelihood of a flooding event is routinely extrapolated by introducing past flooding observations with statistical approaches (Rodriguez-Morata et al., 2016; Tanaka et al., 2017). However, rainfall/flooding gauge records are regularly restricted in terms of timeline length and poorly representative of these extremes in some watersheds. Subsequently, this has led to a high level of uncertainty in flood frequency analysis (Toonen, 2015; Gado and Nguyen, 2016). Thus, in situ reconstructions of extreme flooding magnitudes and frequencies depending on geological archives that document real long-term 
information are required to improve the precision and reliability of estimations (Baker, 1987; Baker et al., 2002; Benito et al., 2010, 2011, 2015).

Past extreme flooding deposits (EFDs) constitute a fundamental source for in situ reconstructions of peak discharges and stages through numerous large flooding processes in different ranges (Baker, 2006, 2008). Once fluvial flooding events have receded, EFDs are embedded in some aeolian loess-soil sequences, and subsequently preserved in the long-term on riverbanks or terraces located on China's Loess Plateau (Huang et al., 2009, 2010, 2011; Guo et al., 2015). Recent studies have established the visual characteristics and sedimentological criteria for identifying EFDs from sediments generated in other earth surface processes along river valleys (Huang et al., 2012, 2013, 2017; Liu et al., 2015). Based on the elevation and thickness of EFDs, real peak discharges and stages of past extreme fluvial flooding events are simulated using two methods: firstly, the Slope-Area Method (SAM); and secondly, the Standard Step Method (STM). These are combined with geomorphological, sedimentological, hydrological and geochronological approaches.

Dating of extreme flooding events determined by the Optically Stimulated Luminescence (OSL) approach is useful to explore the rhythm of flooding occurrence and understand the fluvial hydrological system's response to the Asian summer monsoon. A long-term watershed-scale flooding sequence is built that incorporates extreme flooding events. This can not only greatly extend the gauged time series and improve representativeness for flooding databases, but also eliminate the uncertainty of flood risk assessments. Furthermore, it provides a sound basis for design-flood and 
check-flood as required by large-scale hydraulic structures.

The BLH River watershed is located in the hilly and gully regions of the Loess Plateau, where it poses acute problems relevant to heavy river loads and frequent fluvial flooding disasters. The ever-increasing probability and magnitude of extreme fluvial flooding is an urgent and persistent problem and has been for decades in this watershed. However, only a few investigations have been undertaken on previous extreme flooding events. Consequently, there is still lack of knowledge concerning the long-term sequence in the downstream reaches of the BLH River. Thus, continuous research on long-term extreme fluvial flooding is essential to enrich flooding datasets for flood prevention, control, and flood management in the watershed.

Together with some successfully conducted field trips, the novel EFDs in the lower BLH River were highlighted. The primary objectives of this paper are to: (i) clarify extreme fluvial flooding events based on EFDs by visual characteristics and sedimentological proxy indices; (ii) create a chronological framework of extreme fluvial flooding events by OSL dating in combination with our previous works; (iii) reconstruct peak discharges and stages of extreme fluvial flooding in-situ with hydrological models; and (iv) establish a novel local long-term flooding sequence and interpret the response of the river system to the Asian summer monsoon.

\section{Regional setting}

The BLH River is one of largest tributaries of the Yellow River with a length of $680.3 \mathrm{~km}$ and watershed area of $26905 \mathrm{~km}^{2}$. The river's hydrological network 
appears to have typically dendritic pattern forms and flows through the central Loess Plateau (Fig. 1a, b). The upstream that lies in the loess hilly-gully region is where the fluvial sediment originates. The sediment load transported by the river is $2.8 \times 10^{7}$ tons per year most of which is suspended sediment load made up of fine clay- and silt-sized particles (Zhang et al., 2015b; Guo et al., 2017). The midstream is located in the loess tableland area with a length of $229.3 \mathrm{~km}$ and mean channel slope of $2.2 \%$. The downstream that belongs to the Guanzhong Plain where it meets the Weihe River is often struck by flooding events in summer. The mean annual runoff volume of this river is $9.3 \times 10^{8} \mathrm{~m}^{3}$. These EFDs cannot stay indefinitely in the upper reaches given the steep slopes and supercritical flows. However, they are always preserved over the long-term in flood-prone areas of the middle reaches and lower reaches. Three extreme flooding sites, specifically Liangmaocun (LMC), Zhangjiachuan (ZJC) and Caihezhan (CHZ) (Zhang et al., 2015b) were found in the midstream and one new site, i.e. Xipocun (XPC) was discovered in the downstream (Fig. 1b). 


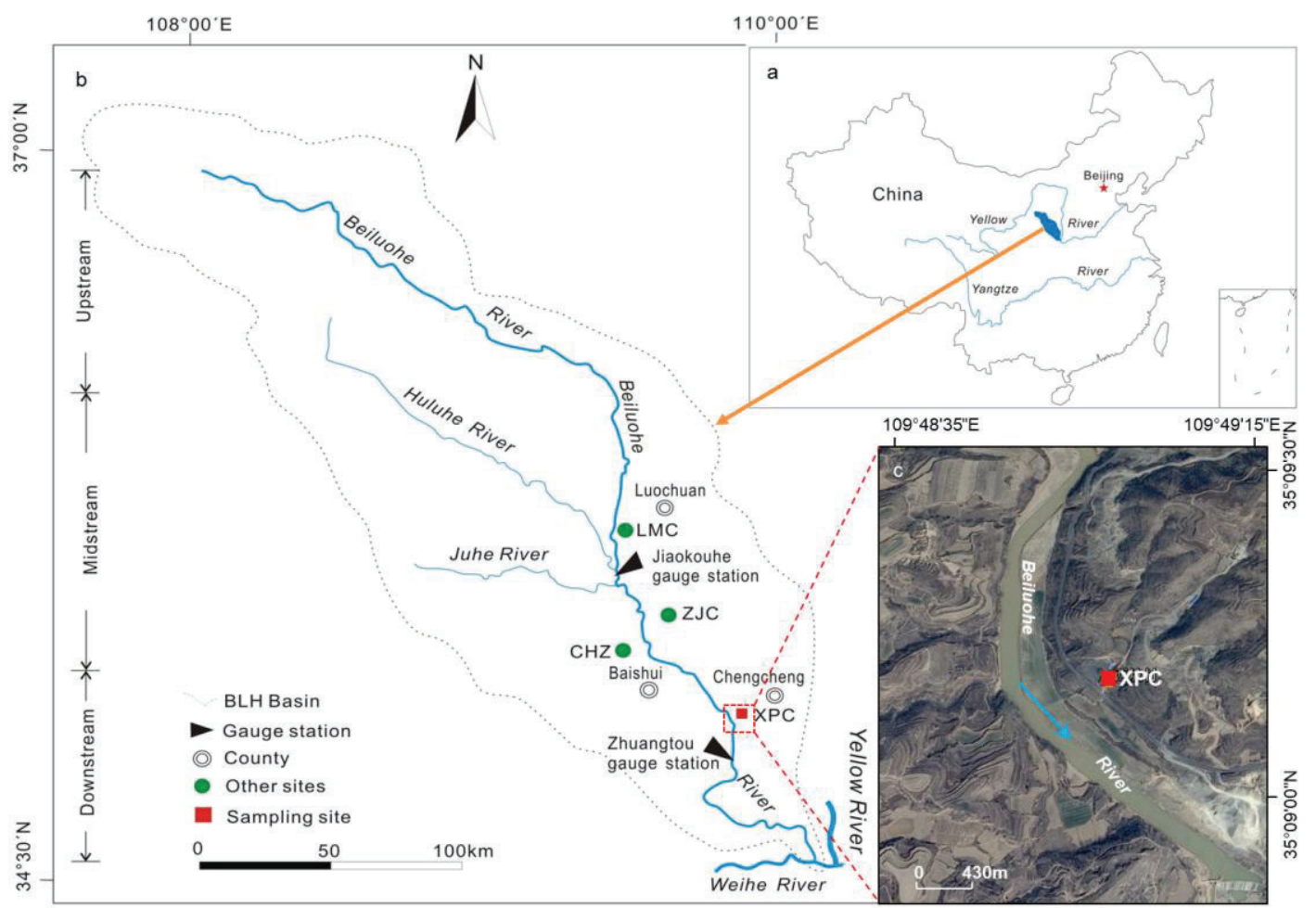

Fig. 1. (a) Map showing the Beiluohe (BLH) River watershed in the middle reaches of Yellow

River. (b) Site map showing locations of extreme flooding sites including Liangmaocun (LMC),

Zhangjiachuan (ZJC), Caihezhan (CHZ) in the midstream and Xipocun (XPC) in the downstream of BLH River and gauge stations; (c) Topographical map of the XPC sampling site downloaded from Google Earth.

The BLH River watershed is located in a temperate continental monsoon climatic regime. The main feature of this climate is the inhomogeneous distribution of regional precipitation in different seasons. Typically, the rainy season lasts from June to September with $75.8 \%$ of total annual rainfall taking place intensively in this period. Mean annual precipitation is $550.7 \mathrm{~mm}$, but annual fluctuations in rainfall are large in parts of this watershed. For instance, the maximum precipitation was $838.1 \mathrm{~mm}$ in 1964 and the minimum precipitation was $287.3 \mathrm{~mm}$ in 1996. As far as the extension 
of the summer Western Pacific Subtropical High (WPSH) and superposition of multiple regional rainstorms are concerned, riverbank flooding is the most devastating natural disaster in this watershed each year. They are accompanied with a single peak, which is a fine peak-shaped flow-duration curve and comprising an anticlockwise loop rating that characterizes the stage-discharge relationship.

Annual maximum flood peak discharge records for Zhuangtou gauge station $\left(35^{\circ}\right.$ $00^{\prime} \mathrm{N}, 109^{\circ} 50^{\prime} \mathrm{E}$ ) (Fig. 1a) are available for the 60 years covering 1933 to 2000. Suspended sediment data series indicated that the BLH River has a mean suspended sediment concentration (SSC) of $119 \mathrm{~kg} / \mathrm{m}^{3}$ and the highest SSC of $1190 \mathrm{~kg} / \mathrm{m}^{3}$ measured at Zhuangtou station in 1950. The largest modern flood with peak discharge of $6280 \mathrm{~m}^{3} / \mathrm{s}$, peak stage rising of $2.3 \mathrm{~m}$, and the runoff volume reaching up to $1.9 \times 10^{8} \mathrm{~m}^{3}$ during the flooding process occurred at Zhuangtou station on $1 \mathrm{st}$ September, 1994. Two historical floods with peak discharges of $5000 \mathrm{~m}^{3} / \mathrm{s}$ and 10 $700 \mathrm{~m}^{3} / \mathrm{s}$ occurred in 1662 and 1856 , respectively. The Zhuangtou gauge station is the closest station with a distance of $17 \mathrm{~km}$ from the XPC site.

\section{Methodology}

\subsection{Sedimentation method}

Clues to extreme flooding events can be found with use of approved sedimentological methods. Extreme fluvial flooding investigations were conducted along the BLH River in 2008-2016. Diverse EFDs sites were discovered in the downstream reaches and identified through sedimentological and paleohydrological 
criteria in our previous studies (Fig. 1b). Two EFDs beds inserted into a Holocene perpendicular loess-soil sequence were newly exposed and measured at the XPC site in Chengcheng in the lower reaches of the BLH River (Fig. 1b and c). The XPC profile is located at the trailing edge of the second river terrace $\left(\mathrm{T}_{2}\right)$ and rapidly pinches out along the slope direction on the left riverbank. The front-end of the first riverbank terrace $\left(T_{1}\right)$ is ca. (Circa) $10 \mathrm{~m}$, and that of the second terrace $\left(T_{2}\right)$ is ca. 16 $\mathrm{m}$ higher than the normal water level of the BLH River.

Based on the micro-topographical observations and sedimentological comparisons, visual characteristics, color difference, texture and structure, and stratigraphic subdivisions of the XPC profile are described and shown in Table 1. Under the surface, the XPC profile was divided into five stratigraphies (Fig. 2). The EFD1 unit of $80 \mathrm{~cm}$ thickness and EFD2 unit of $45 \mathrm{~cm}$ thickness were inter-bedded between slope deposits (SD) and separated by lithosols with some breccia, indicating their formation in two different periods. The EFD1 unit contains eight thin sub-layers that are wavy horizontal beddings, and the EFD2 unit includes two sub-layers which are parallel beddings. Stratigraphic relationships illustrate that each EFD unit represents an extreme flooding event.

\section{Table 1}

Stratigraphic subdivisions and sedimentary descriptions of the XPC profile with the EFDs in the downstream of the BLH River.

\begin{tabular}{clll}
\hline Depth $(\mathrm{cm})$ & $\begin{array}{l}\text { Stratigraphic } \\
\text { subdivisions }\end{array}$ & \multicolumn{2}{l}{ Sedimentary descriptions } \\
\hline $0 \sim 40$ & Slope deposit (SD1) Grey, granular structure, coarse sand with some breccias,
\end{tabular}




$\begin{array}{lll} & & \\ & & \text { ploughed modern soil, many plant roots, badly sorted. } \\ & \text { Consists of two rippled laminated extreme flooding deposit beds, } \\ & \text { towards the slope edges, thickness of the upper layer is } 10 \mathrm{~cm},\end{array}$

Sediment samples were collected every $5 \mathrm{~cm}$ along the XPC section. Multiple sedimentary proxy indices, including grain-size distribution (GSD), magnetic susceptibility (MS), Loss-on-Ignition (LOI), and Calcium carbonate $\left(\mathrm{CaCO}_{3}\right)$ contents of air-dried sediment samples were determined in the Shaanxi Normal University laboratory. GSDs were measured by a Malvern Mastersizer-S Laser Analyzer with $\left(\mathrm{NaPO}_{3}\right)_{6}$ as a dispersant after pretreatment with $10 \mathrm{ml} 10 \% \mathrm{H}_{2} \mathrm{O}_{2}$ to remove organic matter and $10 \mathrm{ml} \mathrm{10 \%} \mathrm{HCl}$ to resolve calcium carbonate (Huang et al., 2012, 2013). Grain-size statistical indices (GSI), such as median $(M d)$, mean $(M z)$, skewness $(S k)$, kurtosis $(K g)$ and sorting $(S)$ were introduced by applying graphic illustrations of depositional environmental information (Friedman et al., 1992). MS was tested on a mass of $10 \mathrm{~g}$ of sediment with Bartington MS2 magnetic susceptibility meter $(0.47 / 4.7 \mathrm{kHz})$. LOI values were calculated after a 4 -hour burn at $550^{\circ} \mathrm{C}$ in a muffle furnace. $\mathrm{CaCO}_{3}$ contents were gauged with an Eijkelkamp 08.53 carbonate analyzer.

\subsection{Dating method}


Chronology of fluvial flooding events is another source of extreme characteristics in a historic framework. Two OSL samples were obtained from the XPC flooding sedimentary layers at depths of $70 \mathrm{~cm}$ and $110 \mathrm{~cm}$. OSL dating on quartz grains between fractions sizes of $40 \mu \mathrm{m}$ and $63 \mu \mathrm{m}$ was carried out by the single aliquot regenerative-dose (SAR) protocol (Murray and Wintle, 2000; Koul et al., 2016) in the TL/OSL dating laboratory of Shaanxi Normal University. All measurements were performed on a Risø-TL/OSL-DA20 dating system and obtained the equivalent dose (De) corresponding to the natural OSL signal. The concentrations of $K, U$, and $T h$ used in calculating OSL ages were measured by neutron activation analysis (Tamura et al., 2007) at the China Institute of Atomic Energy in Beijing. The application program Age.exe (Grün, 2003) ran and generated the results for the OSL dates (Fig. 2). 

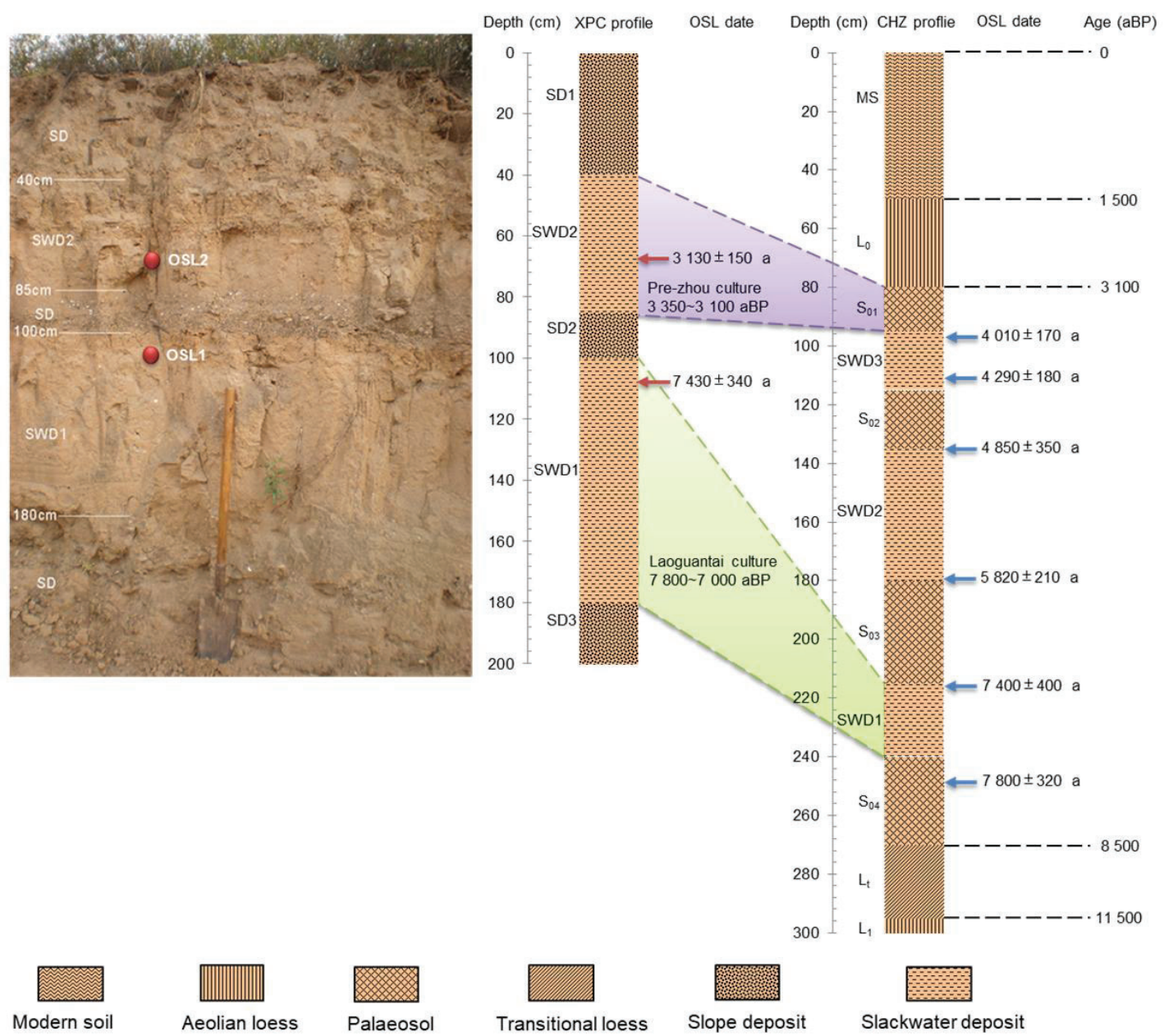

Fig. 2. Stratigraphic subdivisions and OSL dating of the XPC profile correlation with the $\mathrm{CHZ}$ profile in the BLH River watershed. SD: slope deposit, EFD: extreme flooding deposit, MS: modern soil, $\mathrm{L}_{0}$ : recent loess, $\mathrm{S}_{0}$ : palaeosol, $\mathrm{L}_{\mathrm{t}}$ : transitional loess, $\mathrm{L}_{1}$ : the Malan loess.

\subsection{Hydraulic modeling}

Peak stages of extreme flooding were estimated with the slackwater flow depth method (Guo et al., 2017). Each extreme flooding peak stage (PS) is obtained by adopting the bottom elevation of end-point SWDs $(B E)$ and the slackwater depth $(S D)$, which is calculated by the ratio of the SWD thickness $(T)$ to the bulk of suspended sediment load of the flood $(P, \%)$. As a result, the $P S$ can be inferred from equations: 
$P S=B E+S D$ and $S D=T P^{-1}$. Peak discharges of extreme flooding were reconstructed using the Slope-Area Method (SAM) and one-dimensional (1D) Hydrologic Engineering Centre's River Analysis System (HEC-RAS). The Slope-Area method (SAM) based on Manning's empirical formula is written as follows:

$Q=n^{-1} A R^{2 / 3} S^{1 / 2}$

where, the hydraulic radius $R$, which is the quotient of the channel cross-section area $A$ and wetted perimeter $L$, the channel slope $S$, and the empirical roughness coefficient $n$ refer to Manning (Herget and Meurs, 2010; Guan et al., 2016). The multi-dimensional HEC-RAS model requires validate boundary conditions and results in large errors at large spatial scales $\left(>100 \mathrm{~km}^{2}\right)$ while the 1D HEC-RAS model is widely used for the flooding scenario simulation in relatively steady and straight rivers (Singh et al., 2018). Hydraulic features and parameters of the river channel, including geometry, slope gradient and roughness coefficients were measured in situ during field surveys. Manning's roughness coefficients for the main channel and extreme flooding channel on the left and right sides were assigned by reference to the Hydrological Calculation Norms for Hydraulic Engineering in China (GB/T 50095-2014). Channel cross-section geometry and water level surface elevations of the river at the XPC site were monitored using two systems: an electronic rangefinder (Contour-XLR1-LC5279, USA); and GPS in association with large scale topographic maps, these being 1: 10000 and 1:5000.

\section{Results and discussion}




\subsection{Sedimentary environments of EFD}

The texture of sedimentary material provides clues to the process of information and depositional environments (Thorndycraft et al., 2005, 2006; Prieto and Rojas, 2015). At the XPC site, grain-size distribution frequency and probability cumulative curves of EFDs are shown in Fig. 3. EFD1 and EFD2 are consisting primarily of silts ranging in size from $2 \mu \mathrm{m}$ to $63 \mu \mathrm{m}$ (Fig. 3a). The XPC EFDs contain an average proportion of coarse silt size ranging from $16 \mu \mathrm{m}$ to $63 \mu \mathrm{m}$ and this is $42.1 \%$, while that of fine silt size varies from $2 \mu \mathrm{m}$ to $16 \mu \mathrm{m}$ and is $38.6 \%$. However, the sand-sized $(>63 \mu \mathrm{m})$ percentage is $6.9 \%$ and the clay-sized $(<2 \mu \mathrm{m})$ percentage is $12.4 \%$, respectively. Therefore, the chief component of the EFD stratum is coarse silt. Moreover, the curves of the EFDs peak at the coarse silt $(16 \sim 63 \mu \mathrm{m})$ is clearly oriented to the coarse side. The distribution frequency curves of EFDs present as positively skewed and their kurtosis is single and narrow, which confirms that the EFDs are typically well-sorted. The probability of cumulative curves shows the relationship of sediment transport dynamics to populations, indicate that finer EFDs experienced the processes of suspension and truncation points were lower than 200 $\mu \mathrm{m}$ (Fig. 3b). 

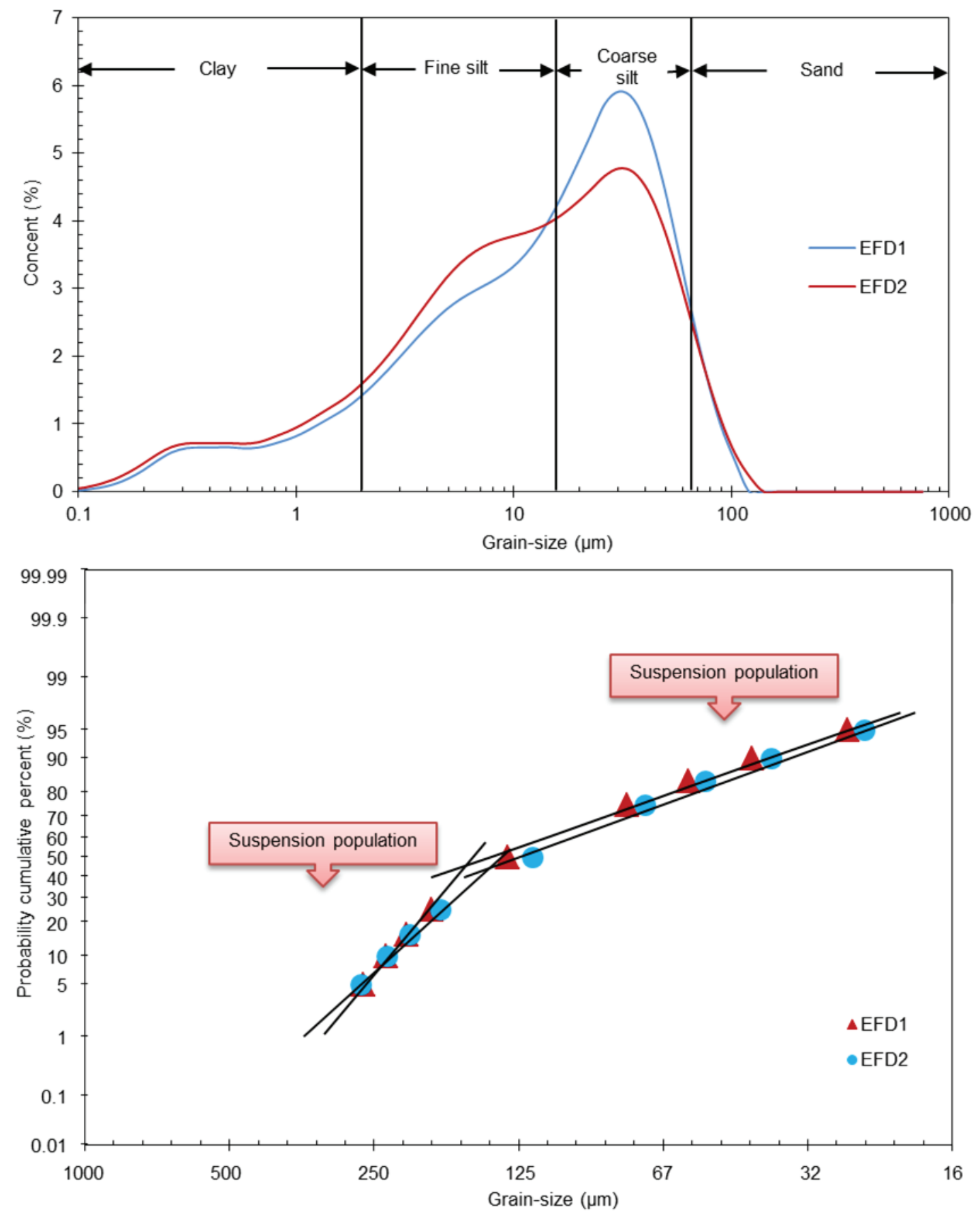

Fig. 3. Grain-size distribution frequency and probability cumulative curves of EFDs at the XPC site in the downstream of the BLH River.

The statistical grain-size indices such as median $(M d)$, mean $(M z)$, standard deviation $(\sigma)$, skewness $(S K)$, kurtosis $(K g)$ and sorting $(S)$ are important for charactering grain-size presented in Table 2. As observed in the table, $M d$ and $M z$ of 
EFDs are $15.5 \mu \mathrm{m}$ and $21.0 \mu \mathrm{m}$, respectively. The ratios of clay to coarse silt range from 0.15 to 0.18 (Table 3 ). In addition, the standard deviation $(\sigma)$ indicates the fluctuations in transportation conditions and depositional environments (Ghosh and Chatterjee, 1994). The higher standard deviation $(\sigma)$ values mean these EFDs experienced fluvial long-distance transportation by high energy flooding. Variation in the kurtosis $(\mathrm{Kg})$ values is a reflection of the flow characteristics of the depositing medium and measures the sorting of sediments (Ghosh and Chatterjee, 1994). The kurtosis $(\mathrm{Kg})$ values of EFDs are less than 3.0 with fewer extreme outliers show that these EFDs are mainly well-sorted. Furthermore, they are mainly composed of fine clayey silt. The nature of EFDs is that at higher flow rates of extreme flooding, all clay and silt are kept in suspension.

\section{Table 2}

Grain-size distribution and statistical indices of EFDs at the XPC site in the downstream of the BLH River.

\begin{tabular}{|c|c|c|c|c|c|c|c|c|c|c|}
\hline $\begin{array}{c}\text { Extreme flooding } \\
\text { deposits }\end{array}$ & $\begin{array}{c}<2 \mu \mathrm{m} \\
(\%)\end{array}$ & $\begin{array}{c}2 \sim 16 \mu \mathrm{m} \\
(\%)\end{array}$ & $\begin{array}{c}16 \sim 63 \mu \mathrm{m} \\
(\%)\end{array}$ & $\begin{array}{c}>63 \mu \mathrm{m} \\
(\%)\end{array}$ & $\begin{array}{l}M d \\
\mu \mathrm{m}\end{array}$ & $\begin{array}{l}M z \\
\mu \mathrm{m}\end{array}$ & $\sigma$ & $S K$ & $K g$ & $S$ \\
\hline EFD2 & 13.21 & 40.98 & 38.70 & 7.10 & 14.01 & 20.02 & 2.08 & 0.24 & 1.01 & 1.42 \\
\hline EFD1 & 11.50 & 36.25 & 45.55 & 6.70 & 16.98 & 22.01 & 1.99 & 0.35 & 1.02 & 1.35 \\
\hline
\end{tabular}

The index of MS does not only represent ferromagnetic mineral contents in deposits, it also reveals the material source, sedimentary dynamics and secondary environmental change of EFDs. LOI is an indicator of organic carbon content (including crystal water) in sediments. $\mathrm{CaCO}_{3}$, as a soluble salt, is a fundamental component of topsoil and sediment in arid and semi-arid regions. These parameters 
are widely used to describe climate change and environmental conditions. Thus, characteristics of EFDs at the XPC site were identified in combination with these proxy indices. MS values of EFDs in the XPC profile were lower than those of the typical aeolian loess $\left(40 \sim 100 \times 10^{-8} \mathrm{~m}^{3} / \mathrm{kg}\right)$ and palaeosol $\left(100 \sim 140 \times 10^{-8} \mathrm{~m}^{3} / \mathrm{kg}\right)$ in the Loess Plateau (Huang et al., 2010). MS and $\mathrm{CaCO}_{3}$ contents of EFD2 were higher than those of EFD1, but the LOI value of EFD2 was lower than that of EFD1 (Table 3). EFDs contain less magnetic mineral, organic matter and calcium carbonate than aeolian loess and palaeosol in the watershed, which suggests that variations in sediments' components were related to depositional environments of saltation and suspension. Moreover, the higher location of the deposition during high flooding stage represents the more powerful uplift force of flooding in the internal hydrodynamics scenario.

\section{Table 3}

Magnetic susceptibility (MS), loss-on-ignition (LOI), $\mathrm{CaCO}_{3}$ content and clay/coarse silt ratio of EFDs at the XPC site in the downstream of the BLH River.

\begin{tabular}{ccccc}
\hline Extreme flooding deposits & $\begin{array}{c}\mathrm{MS} \\
\left(\times 10^{-8} \mathrm{~m}^{3} / \mathrm{kg}\right)\end{array}$ & $\begin{array}{c}\text { LOI } \\
(\%)\end{array}$ & $\begin{array}{c}\mathrm{CaCO}_{3} \text { content } \\
(\%)\end{array}$ & Clay/coarse silt ratio \\
\hline EFD1 & 39.00 & 1.81 & 10.93 & 0.15 \\
EFD2 & 49.70 & 1.62 & 12.12 & 0.18 \\
\hline
\end{tabular}

Together with stratigraphical and sedimentological proxy index, it is noted that the texture of extreme flooding records at the XPC site were well-sorted clayey silt carried in suspension along high-energy extreme flooding currents. Two phases of flooding events in the lower BLH river valley were derived from the suspended 
sediment load in a high location and the relatively stagnant environment of the river. These events were traced through an analysis of these EFDs.

\subsection{Chronology of extreme flooding events}

The chronological framework of the XPC profile was established by OSL dating and pedostratigraphical correlation with the existing well-dated $\mathrm{CHZ}$ profile in the BLH River (Fig. 2). The OSL sample in the upper stratum of EFD1 dated to $7430 \pm$ $340 \mathrm{a}$ in the XPC profile was consistent with typical archives of EFD1 lying between $\mathrm{S}_{04}$ with the base dating of $7890 \pm 320$ a and $\mathrm{S}_{03}$ with the base dating of $7400 \pm 400 \mathrm{a}$ at the CHZ site (Zhang et al., 2015b). It is confirmed that extreme flooding events prevailed in the BLH River watershed during the first flooding phase between 7600 and 7400 a B.P. and this coincided with the flourishing Laoguantai culture (7 800 7 000 a B.P.) according to archeological excavations. In addition, a climatic cooling event documented by high-resolution pollen records from Lake Ugii Nuur in central Mongolia was dated to 7400 a B.P. (Zhang et al., 2018). Contemporary reduction in rainfall was revealed by well-dated, high-resolution stalagmite $\delta^{18} \mathrm{O}$ records from Hoti Cave (H5) in northern Oman of 7400 a B.P. (Neff et al., 2001). The timing of EFD1 suggests extreme flooding events of the BLH River during the mid-Holocene between 7600 and 7400 a B.P. which coincide with higher climate variations.

The second extreme flooding phase recorded by EFD2 with an OSL dating of 3 $130 \pm 150$ a in the XPC profile which corresponded to the $\mathrm{S}_{01}$ layer of the $\mathrm{CHZ}$ profile, 
was laid down between 3200 and 3000 a B.P. At the same time, abrupt monsoonal climate shifts occurred in the late Holocene with colder and drier regimes after the mid-Holocene Climate Optimum over the arid and semi-arid regions (Peng et al., 2005; Huang et al., 2009, 2017). In early Chinese history, this period coincided with the cultural transition from the Shang Dynasty (1 600 1 046 B.C.) to the Pre-dynastic Zhou (1 200 800 B.C.) accompanied by mega-droughts, frequent flooding, drying-up rivers, harvest failures, great famine, plague outbreaks, and social upheavals (Huang et al., 2009). More previous research findings provided ample evidence of extraordinary hydro-climatic events taking place from 3200 a B.P. to 2800 a B.P., which coincided with some extreme flooding events identified in the middle Yellow River and its tributaries, such as the Qishuihe River, Weihe River and Jinghe River (Huang et al., 2010, 2011, 2012, 2013). Furthermore, Nile Delta pollen assemblages were characterized by large shifts in the abundance of Cyperaceae pollen dating to 3 000 a B.P., which reflected extreme regional droughts that affected Middle Eastern civilizations (Bernhardt et al., 2012). It is clear that an abrupt climatic deterioration with more dramatic variability from 3200 to 3000 a B.P. at the end of the mid-Holocene Climate Optimum (Kale et al., 2000; Michael, 2001; Bohorquez et al., 2013; Lillios et al., 2016) was associated with frequent severe droughts and extreme flooding in the Yellow River basin. However, the flooding deposits during 4 200 4 000a B.P. were not discovered in the XPC profile and they may have been scoured by the larger flooding of 3 200 3 000 a B.P. Therefore, two extreme flooding periods, that are, 7 600 7 400 a B.P. and 3 200 3 000 a B.P. in the BLH River watershed, 
coincided with global climatic events and were considered as a response of the regional fluvial system to high climatic variability and instability.

\subsection{In situ reconstruction of extreme flooding}

\subsubsection{Peak stages reconstruction}

Regardless of methods used for a quantitative reconstruction of extreme flooding, the field evidence of flooding peak stage is of first importance (Sheffer et al., 2008; Rodriguez-Morata et al., 2016). Peak stages of two extreme flooding events based on EFDs at XPC site were reconstructed with the slackwater flow depth method (Guo et al., 2017). The end-point of each EFDs bed is above its base level in the $0.70 \sim 1.80 \mathrm{~m}$ range. Elevations of EFDs greatly depend on the river channel morphology and generally vary from $10.0 \mathrm{~m}$ to $15.0 \mathrm{~m}$ above the normal water level in China (Yang et al., 2000). Extreme flooding peak stages are estimated by bottom elevations of EFDs and extreme flooding depths, which are calculated by the ratio of the EFDs' thickness to the bulk of suspended sediment load during flooding. As a result, extreme flooding peak stages for EFD1 and EFD2 at the XPC site are $457.67 \mathrm{~m}$ and $463.67 \mathrm{~m}$ above sea level (a.s.1.), respectively (Table 4).

\section{Table 4}

In situ reconstructed peak discharges of extreme flooding events at the XPC site and other sites in the BLH River watershed 


\begin{tabular}{cccccccc}
\hline \multirow{2}{*}{$\begin{array}{c}\text { Extreme flooding } \\
\text { events }\end{array}$} & $\begin{array}{c}\text { Flooding } \\
\text { peak stages } \\
\text { (m a.s.1.) }\end{array}$ & $\begin{array}{c}\text { Flooding } \\
\text { water } \\
\text { depth } \\
H(\mathrm{~m})\end{array}$ & $\begin{array}{c}\text { Channel } \\
\text { slope }\end{array}$ & $\begin{array}{c}\text { Roughness } \\
\text { values }\end{array}$ & $\begin{array}{c}\text { Cross } \\
\text { section } \\
\text { area } \\
\left(\mathrm{m}^{2}\right)\end{array}$ & $\begin{array}{c}\text { Hydraulic } \\
\text { radius }\end{array}$ & $\begin{array}{c}\text { Peak } \\
\text { discharges }\end{array}$ \\
\hline XPC-EFD1 & 457.67 & 17.27 & 0.0015 & 0.038 & 1987.50 & 11.07 & 9625 \\
XPC-EFD2 & 463.67 & 23.27 & 0.0015 & 0.035 & 2802.30 & 12.73 & 16635 \\
CHZ-EFD1 & 634.80 & 15.45 & 0.0025 & 0.040 & 2081.15 & 11.30 & 12600 \\
CHZ-EFD2 & 635.50 & 16.15 & 0.0025 & 0.040 & 2218.50 & 10.85 & 13600 \\
CHZ-EFD3 & 635.85 & 16.50 & 0.0025 & 0.040 & 2289.27 & 10.95 & 14100 \\
ZJC-EFD1-1 & 605.70 & 28.70 & 0.0014 & 0.055 & 3270.60 & 15.11 & 13810 \\
ZJC-EFD1-3 & 607.00 & 30.00 & 0.0014 & 0.055 & 3553.90 & 16.01 & 15591 \\
LMC-EFD1-1 & 778.40 & 17.50 & 0.0016 & 0.050 & 3044.50 & 11.42 & 12350 \\
LMC-EFD1-5 & 780.00 & 19.10 & 0.0016 & 0.050 & 3471.40 & 12.21 & 14730 \\
\hline
\end{tabular}

\subsubsection{Magnitude reconstruction}

The ultimate objective of palaeoflood hydrology research is to reconstruct the magnitude and frequency of extreme flooding events (Rodriguez-Morata et al., 2016; Scorpio et al., 2018). The peak discharges $(Q)$ of extreme flooding events at the XPC site was estimated by the Slope-Area method (SAM). It evaluates the mean flow velocity in open channels for a uniform, steady, one-dimensional flow condition. Slope $S$ of the BLH River channel at the XPC site is normally parallel to the gradient of the water surface profile, i.e., elevation difference per length measured through an electronic rangefinder and GPS during fieldwork and revised in association with a 1:10 000 scale contour map. Channel morphology data were collected with detailed measurements of water surface, streambed, breadth, depth, and bank full elevations. The bedrock channel reaches of the BLH River provide stable cross-sections through the XPC sampling site for calculation of extreme flooding discharge. The roughness coefficient $n$ depends on boundary conditions of the flooding area such as grain-size of sediments, species categories and crown density of vegetation (Ayvaz et al., 2013; 
Singh et al., 2018). Referring to the hydrological calculation standards for hydraulic engineering in China, the values of roughness coefficient $n$ at the XPC channel are 0.035 and 0.038 . By the Slope-Area method (SAM) which involves the Manning equation, extreme flooding peak discharges are simulated at the XPC site and lie in the interval of $9625 \sim 16635 \mathrm{~m}^{3} / \mathrm{s}$ (Table 4). To assess the flow speed and hydraulic regime caused by extreme flooding, the Froude $\left(F_{r}\right)$ number of flow was adopted as an index of flow status:

$F_{r}=v g^{-1 / 2} H^{-1 / 2}$

where, $v$ is the flow velocity, $g$ is the acceleration due to gravity, and $H$ is the flooding water depth. From the values of $F_{r}$ between 0.47 and 0.49 , this clarified that the reconstructed flooding currents presented higher and strong flowing regimes with suspension transportation.
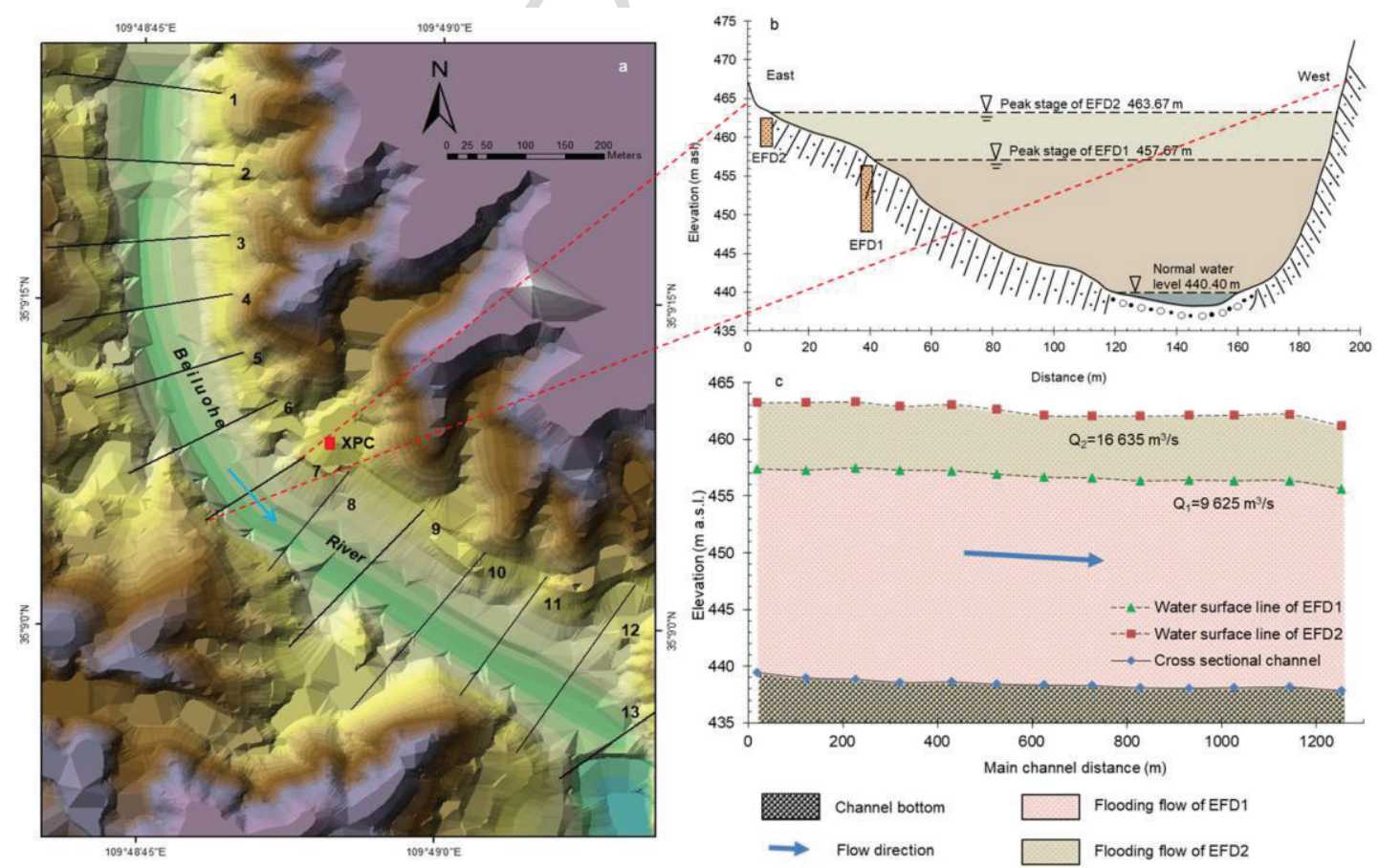

Fig. 4. (a) Cross-section distributions for extreme flooding hydrological reconstruction at the XPC site along the BLH River channel; (b) Cross-sectional morphology and peak stages of extreme flooding; (c) 
Water surface lines and channel bottom of the BLH River at the sampling site.

To avoid errors of simulated discharges caused by a single cross-section, the HEC-RAS version 4.1 for 1D steady flow model with GIS compatibility was put into operation to reconstruct the flooding magnitude (U.S. Army Corps of Engineers, 2010). The 1D energy equation of this model is as follows:

$Z_{2}+Y_{2}+0.5 g^{-1} \alpha_{2} V_{2}^{2}=Z_{1}+Y_{1}+0.5 g^{-1} \alpha_{1} V_{1}^{2}+h_{e}$

where, $Z$ is the elevation of channel, $g$ is the acceleration due to gravity, $Y$ is water depth of the cross-section, $V$ is mean flow velocity, $\alpha$ is kinetic energy correction coefficient, and $h_{e}$ is water head loss. There were 13 cross-sections distributed along the main channel and these were $1.3 \mathrm{~km}$ in length (Fig. 4a); their parameters were imputed in the hydraulic model. The stable bedrock canyon and narrow cliff without a tributary was ideal and critical boundary conditions existed throughout the study location. Cross-section morphologies calibrated based on DEMs and geometric data were imported from ArcGIS 10.0. The HEC-RAS model simulated the water surface profiles of the 13 cross-sections. Peak discharges of extreme flooding were obtained in terms of Manning's $n$ values between 0.035 and 0.040 covering valley floor and margins in the HEC-RAS modeling system. Regarding the elevation of end-point EFDs as the minimum stage of extreme flooding, the minimum peak discharges of 16 $635 \mathrm{~m}^{3} / \mathrm{s}$ and $9625 \mathrm{~m}^{3} / \mathrm{s}$ assessed by STM were well matched with the results simulated by SAM (Table 4). These estimated discharge values of extreme flooding at the $\mathrm{LMC}, \mathrm{ZJC}, \mathrm{CHZ}$, and the XPC sites are 1.5 to 2.6 times larger than the maximum 
gauged discharge of the BLH River (Table 4). However, the discharge results contain an error of $5 \sim 12 \%$ when inputting a $25 \%$ variation in roughness values $(0.75 n$ and $1.25 n)$

Modern mega flooding discharges analog plays a crucial role for checking the validity of estimated extreme flooding discharges. The features of the modern flooding were also simulated by operating the HEC-RAS model. The estimated peak stage of modern flooding at the 7 th cross-section was $453.6 \mathrm{~m}$ a.s.1. and $13.2 \mathrm{~m}$ higher than the normal water level. Compared with observed data that the flooding peak discharge was $6280 \mathrm{~m}^{3} / \mathrm{s}$ and the water stage rose $12.3 \mathrm{~m}$ in 1994 at Zhuangtou gauge station, the simulated peak stage of modern flooding with an error of $7.3 \%$ confirms there is a good agreement with those corresponding observed data. The results again ascertained that the two approaches for reconstructing extreme flooding events were feasible. Furthermore, as put forward by Baker (2006) the reconstructed discharges of extreme flooding events followed the relationship between peak discharge and drainage area of global maximum flooding events were reliable.

\subsection{Long-term frequency reconstruction}

The log-Pearson type (LP) III distribution is the most common method applied to assess the frequency of fluvial flooding and predict the flood design in China. The flooding frequency was estimated at the XPC site in the downstream the BLH River by the discharge-based approach. Annual maximum flooding peak discharges for long-term frequency reconstruction at the Zhuangtou station from 1933 to 2017 are 
shown in Fig. 5b. The relationship between flooding frequencies and their peak discharges without consideration of historical flooding and extreme flooding events is shown in Fig. 5a. In contrast, the curve with a consideration of historical flooding peak discharges of $5000 \mathrm{~m}^{3} / \mathrm{s}(1662)$ and $10700 \mathrm{~m}^{3} / \mathrm{s}$ (1856) shows that peak discharges drastically increase corresponding frequencies $<1 \%$. However, beyond this, the results appear to be significant reduction corresponding frequencies $<1 \%$ due to integrating with the in situ reconstructed extreme flooding events with larger magnitudes and lower frequencies than the gauged and historical flooding. It is clear that the magnitude quantification of long-term extreme flooding events greatly influences the accuracy of low-frequency and large-magnitude flooding. The maximum estimated flooding magnitudes are $16635 \sim 9625 \mathrm{~m}^{3} / \mathrm{s}$ at the 10000 -year timescale on the Chengcheng reach in the downstream BLH River. Flooding frequency analysis involved in 100-year or 1000-year flooding was performed effectively by interpolation instead of conventional extrapolation which overestimates the intensity of low-frequency events. Thus, a long-term flooding frequency curve built as a red line in Fig. 5a provides a credible recurrence of regional flooding risk and design-floods prediction of water conservancy construction in the downstream region of the BLH River.

\section{Conclusions}

Sedimentary environments and dynamic conditions of two units of EFDs (EFD1 and EFD2) found at the XPC site in the downstream BLH River were revealed by 
multiple sedimentation proxy indices. Specifically, deposits were carried in suspension during high-energy extreme flooding currents with a high water level and the river having a relatively stagnant environment. The applications of the OSL dating technique and stratigraphic correlations determined that two extreme flooding phases documented by EFDs were $7600 \sim 7400$ and 3 200 3 000 a B.P. Through the Slope-Area Method and HEC-RAS model, the in situ reconstructed magnitudes of extreme flooding were $16635 \mathrm{~m}^{3} / \mathrm{s}$ and $9625 \mathrm{~m}^{3} / \mathrm{s}$. A novel long-term peak discharge-frequency curve was established with gauged, historical and extreme flooding data and showed that the reconstructed maximum flooding discharge is 16 $635 \mathrm{~m}^{3} / \mathrm{s}$ on the 10000 -year timescale in the BLH River downstream. Quantification magnitudes and frequencies of long-term extreme flooding events revealed the main driving mechanisms between hydrological extremes and regional monsoonal climate fluctuations. The BLH River's response to regional climatic variations in the Holocene period during the watershed scale was the homochronous extreme flooding in middle and lower reaches. These extreme flooding periods sometimes were followed by frequent heavy rainfall, and sometimes experienced prolonged drought, which bought about extreme flooding or drying up of river systems.

Therefore, periods of extreme flooding occurrence under climate abnormality scenarios characterized with high frequencies of hydrological extremes resembled those of historical periods or the present. Thus, two extreme flooding events in the BLH River are helpful in understanding the effects of global climatic variations on river system dynamics. Extreme flooding in situ reconstruction provides a real 
long-term record including magnitudes and frequencies information. This not only improves the reliability for risk assessment and hydrological design, but also predicts the response of local fluvial systems to the non-stationarity of climate at watershed scales. Further study on simulation of extreme flooding events with magnitudes and frequencies in different scenarios and applied for local inundation maps is necessary.

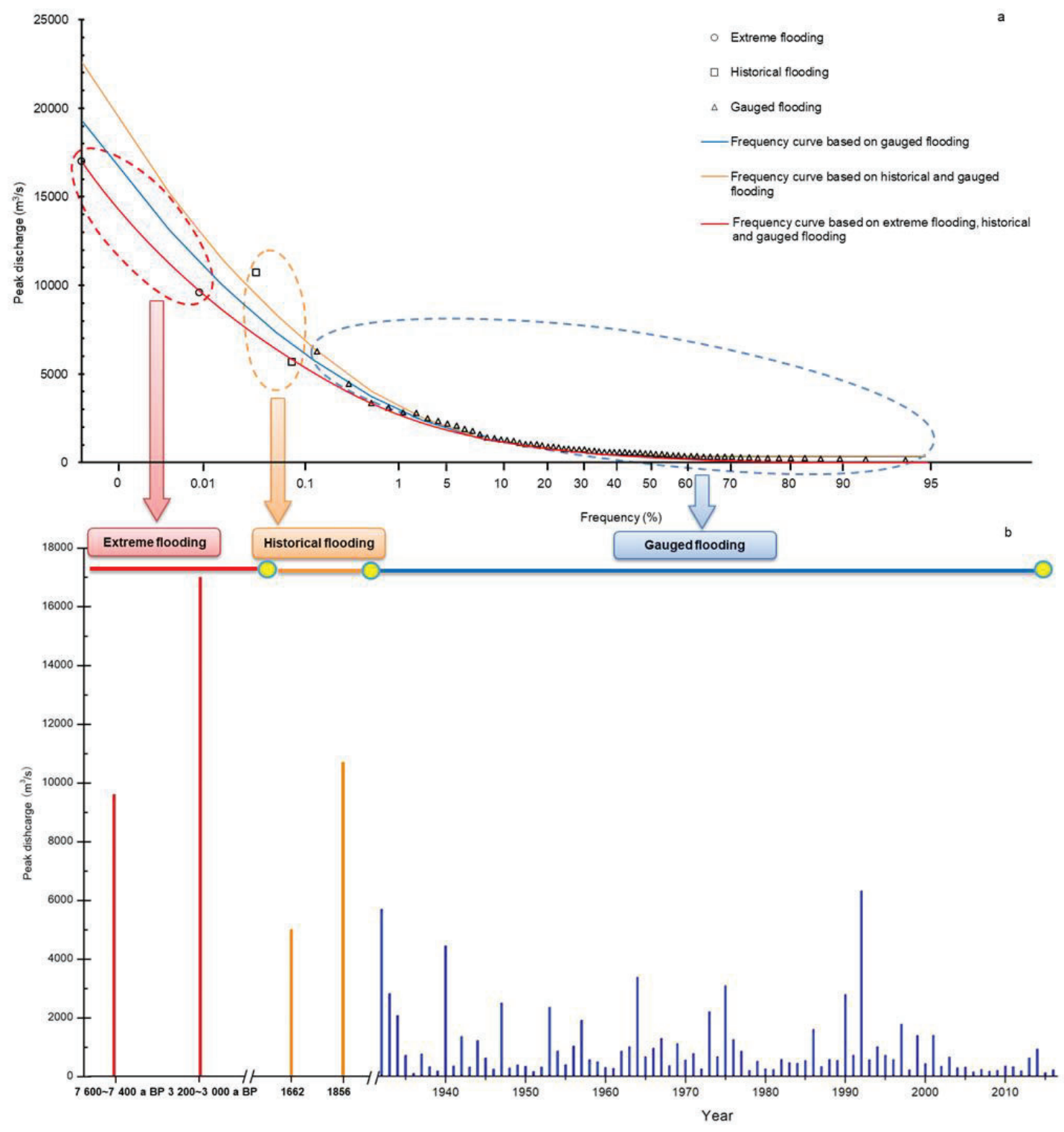

Fig. 5. (a) Relationship between flooding frequency-peak discharge and a long-term frequency curve was established by incorporating gauged flooding (1933 2017), historical flooding (1662 and 1856), 
and extreme flooding data at the Zhuangtou gauge station in the BLH River watershed; (b) Non-successive flooding data at the Zhuangtou gauge station in the BLH River watershed.

\section{Acknowledgements}

This study was supported by the grants from the National Science Foundation of China (No. 41601020 and 41471071), China Postdoctoral Science Foundation (No. 2017M623113), and the Fundamental Research Funds for the Central Universities of China (No. GK201601006).

\section{References}

Apurv, T., Mehrotra, R., Sharma, A., Goyal, M.K., Dutta, S., 2015. Impact of climate change on floods in the Brahmaputra basin using CMIP5 decadal predictions. J. Hydrol. 527, 281-291. https://doi.org/10.1016/j.jhydrol.2015.04.056.

Ayvaz, M.T., 2013. A linked simulation-optimization model for simultaneously estimating the Manning's surface roughness values and their parameter structures in shallow water flows. J. Hydrol. 500, 183-199. https://doi.org/10.1016/j.jhydrol.2013.07.019.

Baker, V.R., 1987. Paleoflood hydrology and extraordinary flood events. J. Hydrol. 96, 79-99. https://doi.org/10.1016/0022-1694(87)90145-4.

Baker, V.R., Webb, R.H., House, P.K., 2002. The scientific and societal value of paleoflood hydrology. In: House, P.K., Webb, R.H., Baker, V.R., Levish, D.R. (Eds.), Ancient Floods, Modern Hazards: Principles and Applications of Paleoflood Hydrology, Water Science and Application Series. 5, 127-146. https://doi.org/10.1029/WS005p0001. 
Baker, V.R., 2006. Palaeoflood hydrology in a global context. Catena. 66, 161-168. https://doi.org/10.1016/j.catena.2005.11.016.

Baker, V.R., 2008. Palaeoflood hydrology: origin, progress, prospects. Geomorphology. 101, 1-13. https://doi.org/10.1016/j.geomorph.2008.05.016.

Beniston, M., Stoffel, M., Hill, M., 2011. Impacts of climatic change on water and natural hazards in the Alps: can current water governance cope with future challenges? Examples from the European “ACQWA” project. Environ. Sci. Pol. 14, 734-743. https://doi.org/10.1016/j.envsci.2010.12.009.

Benito, G., Rico, M., Sánchez-Moya, Y., Sopeña, A., Thorndycraft, V.R., Barriendos, M., 2010. The impact of late Holocene climatic variability and land use change on the flood hydrology of the Guadalentín River, southeast Spain. Glob. Planet. Chang. 70, 53-63. https://doi.org/10.1016/j.gloplacha.2009.11.007.

Benito, G., Thorndycraft, V.R., Rico, M., Sánchez-Moya, Y., Sopeña, A., Botero, B.A., Machado, M.J., Davis, M., Pérez-González, A., 2011. Hydrological response of a dryland ephemeral river to southern African climatic variability during the last millennium. Quat. Res. 75, 471-482. https://doi.org/10.1016/j.yqres.2011.01.004.

Benito, G., Macklin, M.G., Zielhofer, C., Jones, A.F., Machado, M.J., 2015. Holocene flooding and climate change in the Mediterranean. Catena. 130, 13-33. https://doi.org/10.1016/j.catena.2014.11.014.

Bernhardt, C.E., Horton, B.P., Stanley, J.D., 2012. Nile Delta vegetation response to Holocene climate variability. Geology. 40, 615-618. https://doi.org/10.1130/G33012.1.

Bohorquez, P., García-García, F., Pérez-Valera, F., Martínez-Sánchez C., 2013. Unsteady two-dimensional paleohydraulic reconstruction of extreme floods over the last $4000 \mathrm{yr}$ in Segura 
River, southeast Spain. J. Hydrol. 477, 229-239. https://doi.org/10.1016/j.jhydrol.2012.11.031.

Friedman, G.M., Sanders, J.E., Kopaska-Merkel, D.C., 1992. Principals of sedimentary deposits. Macmillan, New York, pp. 36-42.

Gado, T.A., Nguyen, V.T.V., 2016. An at-site flood estimation method in the context of nonstationarity II. Statistical analysis of floods in Quebec. J. Hydrol. 535, 722-736. https://doi.org/10.1016/j.jhydrol.2015.12.064.

Ghosh, S.K., Chatterjee, B.K., 1994. Depositional mechanisms as revealed from grain-size measures of the palaeoproterozoic kolhan siliciclastics, Keonjhar District, Orissa, India. Sediment Geology. 89, 182-196._https://doi.org/10.1016/0037-0738(94)90093-0.

Grün, R., 2003. Age. exe computer program for the calculation of luminescence dates. Unpublished computer program RSES, Canberra, Australia.

Guan, M.F., Carrivick, J., Wright, N.G., Sleigh, P.A., Staines, K.E.H., 2016. Quantifying the combined effects of multiple extreme floods on river channel geometry and on flood hazards. J. Hydrol. 538, 256-268. https://doi.org/10.1016/j.jhydrol.2016.04.004.

Guo, Y.Q., Huang, C.C., Pang, J.L., Zha, X.C., Zhou, Y.L., Wang, L.S. Zhang, Y.Z., Hu, G.M., 2015. Investigating extreme flood response to Holocene palaeoclimate in the Chinese monsoonal zone: A palaeoflood case study from the Hanjiang River. Geomorphology. 238, 187-197. https://doi.org/10.1016/j.geomorph.2015.03.014.

Guo, Y.Q., Huang, C.C., Pang, J.L., Zhou, Y.L., Zha, X.C., Mao, P.N., 2017. Reconstruction palaeoflood hydrology using slackwater flow depth method in the Yanhe River valley, middle Yellow River basin, China. J. Hydrol. 544, 156-171. https://doi.org/10.1016/j.jhydrol.2016.11.017

Herget, J., Meurs, H., 2010. Reconstructing peak discharges for historic flood levels in the city of 
Cologne, Germany. Glob. Planet. Chang. 70, 108-116. https://doi.org/10.1016/j.gloplacha.2009.11.011.

Huang, C.C., Pang, J.L., Su, H.X., Li, S.L., Ge, B.W., He, Z., Li, X.Y., Yang, Y.M., Zhu, Y.Z., 2009. Holocene environmental change inferred from the loess-palaeosol sequences adjacent to the floodplain of the Yellow River, China. Quat. Sci. Rev. 28, 2633-2646. https://doi.org/10.1016/j.quascirev.2009.05.024.

Huang, C.C., Pang, J.L., Zha, X.C., Zhou, Y.L., Su, H.X., Li, Y.Q., 2010. Extraordinary floods of 4 100-4 000 a BP recorded at the Late Neolithic Ruins in the Jinghe River Gorges, middle reach of the Yellow River, China. Palaeogeogr. Palaeoclimatol. Palaeoecol. 28, 1-9. https://doi.org/10.1016/j.palaeo.2010.02.003.

Huang, C.C., Pang, J.L., Zha, X.C., Su, H.X., Jia, Y.F., 2011. Extraordinary floods related to the climatic event at 4200 a on the Qishuihe River, middle reaches of the Yellow River, China. Quat. Sci. Rev. 30, 460-468. https://doi.org/10.1016/j.quascirev.2010.12.007.

Huang, C.C., Pang, J.L., Zha, X.C., Zhou, Y.L., Su, H.X., Zhang, Y.Z., Wang, H.S., Gu, H.L., 2012. Holocene palaeoflood events recorded by slackwater deposits along the lower Jinghe River valley, middle Yellow River basin, China. J. Quat. Sci. 27, 485-493. https://doi.org/10.1002/jqs.2536.

Huang, C.C., Pang, J.L., Zha, X.C., Zhou, Y.L., Yin, S.Y., Su, H.X., Zhou, L., Yang, J.C., 2013. Extraordinary hydro-climatic events during the period AD 200-300 recorded by slackwater deposits in the upper Hanjiang River valley, China. Palaeogeogr. Palaeoclimatol. Palaeoecol. 374, 274-283. https://doi.org/10.1016/j.palaeo.2013.02.001.

Huang, C.C., Zhou, Y.L., Zhang, Y.Z., Guo, Y.Q., Pang, J.L., Zhou, Q., Liu, T., Zha, X.C., 2017. Comment on "Outburst flood at 1920 BCE supports historicity of China's Great Flood and the Xia 
dynasty”. Science. 355 (6332), pp1382. https://doi.org/10.1126/science.aak9657.

IPCC, 2013. Summary for policymakers. In: Stocker, T.F., Qin, D., Plattner, G.-.K., Tignor, M., Allen, S.K., Boschung, J., Nauels, A., Xia, Y., Bex, V., Midgley, P.M. (Eds.), Climate Change 2013: The Physical Science Basis, Contribution of Working Group I to the Fifth Assessment Report of the Intergovernmental Panel on Climate Change. Cambridge University Press, Cambridge, United Kingdom and New York, NY USA.

Kale, V.S., Singhvi, A.K., Mishra, P.K., Banerjee, D., 2000. Sedimentary records and luminescence chronology of late Holocene palaeofloods in the Luni River, Thar Desert, northwest India. Catena. 40, 337-358. https://doi.org/10.1016/S0341-8162(00)00091-6.

Koul, D.K., Pagonis, V., Patil, P., 2016. Reliability of single aliquot regenerative protocol (SAR) for dose estimation in quartz at different burial temperatures: A simulation study. Radiat. Meas. 91, 28-35. https://doi.org/10.1016/j.radmeas.2016.04.002.

Lillios, K.T., Blanco-González, A., Drake, B.L., López-Sáez, J.A., 2016. Mid-late Holocene climate, demography, and cultural dynamics in Iberia: A multi-proxy approach. Quat. Sci. Rev. 135, 138-153. https://doi.org/10.1016/j.quascirev.2016.01.011.

Liu, T., Huang, C.C., Pang, J.L., Zha, X.C., Zhou, Y.L., Zhang, Y.Z., Ji, L., 2015. Late Pleistocene and Holocene palaeoflood events recorded by slackwater deposits in the upper Hanjiang River valley, China. J. Hydrol. 529, 499-510. https://doi.org/10.1016/j.jhydrol.2014.11.075.

Liu, X.N., Liu, Z.D., Zhang, Y., Jiang, B.F., 2016. Quantitative analysis of burden of bacillary dysentery associated with floods in Hunan, China. Sci. Total Environ. 547, 190-196. https://doi.org/10.1016/j.scitotenv.2015.12.160.

Michael, J.G., 2001. Large floods and climatic change during the Holocene on the Ara River, central 
Japan. Geomorphology. 39, 21-27. https://doi.org/10.1016/S0169-555X(01)00049-6.

Murray, A.S., Wintle, A.G., 2000. Luminescence dating of quartz using an improved single-aliquot regenerative-dose $\quad$ protocol. $\quad$ Radiat. $\quad$ Meas. $\quad 32, \quad$ 57-63. https://doi.org/10.1016/S1350-4487(99)00253-X.

Neff, U., Burns, S.J., Mangini, A., Mudelsee, M., Fleitmann, D., Matter, A., 2001. Strong coherence between solar variability and the monsoon in Oman between 9 and 6 kyr ago. Nature. 411, 290-293. https://doi.org/10.1038/35077048.

Peng, Y.J., Xiao, J.L., Nakamura, T., Liu, B.L., Inouchi, Y., 2005. Holocene East Asian monsoonal precipitation pattern revealed by grain-size distribution of core sediments of Daihai Lake in Inner Mongolia of north-central China. Earth Planet. Sci. Lett. 233, 467-479. https://doi.org/10.1016/j.eps1.2005.02.022.

Prieto, M.R., Rojas, F., 2015. Determination of droughts and high floods of the Bermejo River (Argentina) based on documentary evidence (17th to 20th century). J. Hydrol. 529, 676-683. https://doi.org/10.1016/j.jhydrol.2015.06.035.

Rodriguez-Morata, C., Ballesteros-Cánovas, J.A., Trappmann, D., Beniston, M. Stoffel, M., 2016. Regional reconstruction of flash flood history in the Guadarrama range (Central System, Spain). Sci. Total Environ. 550, 406-417. https://doi.org/10.1016/j.scitotenv.2016.01.074.

Scorpio, V., Crema, S., Marra, F., Righini, M., Ciccarese, G., Borga, M., Cavalli, M., Corsini, A., Marchi, L., Surian, N., Comiti, F., 2018. Basin-scale analysis of the geomorphic effectiveness of flash floods: A study in the northern Apennines (Italy). Sci. Total Environ. 640-641, 337-351. https://doi.org/10.1016/j.scitotenv.2018.05.252.

Sheffer, N.A., Rico, M., Enzel, Y., Benito, G., Grodek, T., 2008. The palaeoflood record of the Gardon 
River, France: a comparison with the extreme 2002 flood event. Geomorphology. 98, 71-83. https://doi.org/10.1016/j.geomorph.2007.02.034

Singh, N.K., Wemple, B.C., Bomblies, A., Ricketts, T.H., 2018. Simulating stream response to floodplain connectivity and revegetation from reach to watershed scales: Implications for stream management. Sci. Total Environ. 633, 716-727. https://doi.org/10.1016/j.scitotenv.2018.03.198.

Stoffel, M., Tiranti, D., Huggel, C., 2014. Climate change impacts on mass movements-case studies from the European Alps. Sci. Total Environ. 493, 1255-1266. https://doi.org/10.1016/j.scitotenv.2014.02.102.

Tamura, T., Saito, Y., Sieng, S., Ben, B., Kong, M., Choup, S., Tsukawaki, S., 2007. Depositional facies and radiocarbon ages of a drill core from the Mekong River lowland near Phnom Penh, Cambodia: Evidence for tidal sedimentation at the time of Holocene maximum flooding. J. Asian Earth Sci. 29, 585-592. https://doi.org/10.1016/j.jseaes.2006.03.009.

Tanaka, T., Tachikawa, Y., Ichikawa, Y., Yorozu, K., 2017. Impact assessment of upstream flooding extreme flood frequency analysis by incorporating a flood-inundation model for flood risk. J. Hydrol. 554, 370-382. https://doi.org/10.1016/j.jhydrol.2017.09.012.

Taye, M.T., Willems, P., Block, P., 2015. Implications of climate change on hydrological extremes in the Blue Nile basin: A review. J. Hydrol. 4, 280-293. https://doi.org/10.1016/j.ejrh.2015.07.001.

Thorndycraft, V.R., Benito, G., Rico, M., 2005. A long-term flood discharge record derived from slackwater flood deposits of the Llobregat River, NE Spain. J. Hydrol. 313, 16-31. https://doi.org/10.1016/j.jhydrol.2005.02.003.

Thorndycraft, V.R., Benito, G., 2006. The Holocene fluvial chronology of Spain: evidence from a newly compiled radiocarbon database. Quat. Sci. Rev. 25, 223-234. 
https://doi.org/10.1016/j.quascirev.2005.07.003.

Toonen, W.H.J., 2015. Flood frequency analysis and discussion of non-stationarity of the Lower Rhine flooding regime (AD1350-2011): Using discharge data, water level measurements, and historical records. J. Hydrol. 528, 490-502. https://doi.org/10.1016/j.jhydrol.2015.06.014.

U.S. Army Corps of Engineers, 2010. http://www.hec.usace.army.mil/software/hec-ras.

Wang, Y.J., Gao, C., Zhai, J.Q., Li, X.C., Su, B.D., Hartmannd, H.K., 2014. Spatio-temporal changes of exposure and vulnerability to floods in China. Adv. Clim. Chang. Res. 5(4), 197-205. https://doi.org/10.1016/j.accre.2015.03.002.

Xu, Y., Zhang, B., Zhou, B., Dong, S., Yu, L., Rouke, L., 2014. Projected flood risks in China based on CMIP5. Adv. Clim. Chang. Res. 5 (2), 57-65. https://doi.org/10.3724/SP.J.1248.2014.057.

Yang, D.Y., Yu, G., Xie, Y.B., Zhan, D.J., Li, Z.J., 2000. Sedimentary records of large Holocene floods from the middle reaches of the Yellow River, China. Geomorphology. 33, 73-88. https://doi.org/10.1016/S0169-555X(99)00111-7.

Zhang, S.X., Guo, Y.K., Wang, Z.W., 2015a. Correlation between flood frequency and geomorphologic complexity of rivers network-A case study of Hangzhou China. J. Hydrol. 527, 113-118. https://doi.org/10.1016/j.jhydrol.2015.04.060.

Zhang, Y.Z., Huang, C.C., Pang, J.L., Zha, X.C., Zhou, Y.L., Wang, X.Q., 2015b. Holocene palaeoflood events recorded by slackwater deposits along the middle Beiluohe River valley, middle Yellow River basin, China. Boreas. 44, 127-138. https://doi.org/10.1111/bor.12095.

Zhang, Q., Gu, X.H., Singh, V.P., Liu, L., Kong, D.D., 2016. Flood-induced agricultural loss across China and impacts from climate indices. Glob. Planet. Chang. 139, 31-43. https://doi.org/10.1016/j.gloplacha.2015.10.006. 
Zhang, D.L., Feng, Z.D., 2018. Holocene climate variations in the Altai Mountains and the surrounding areas: A synthesis of pollen records. Earth-Science Reviews. 185, 847-869. https://doi.org/10.1016/j.earscirev.2018.08.007. 